\title{
HALLUX PROXIMAL PHALANX FRACTURE IN ADULTS: AN OVERLOOKED DIAGNOSIS
}

\section{FRATURA DA FALANGE PROXIMAL DO HÁLUX EM ADULTOS: UM DIAGNÓSTICO ESQUECIDO}

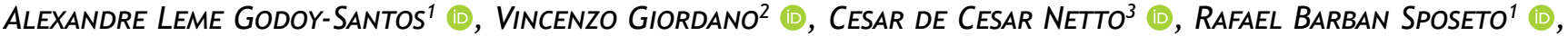

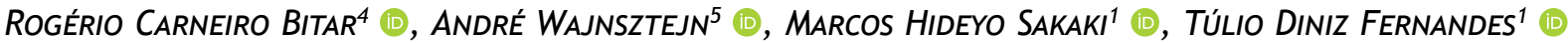

1. Lab. Prof Mario Manlio Marco Napoli, Hospital das Clinicas HCFMUSP, Faculdade de Medicina, Universidade de Sao Paulo, Sao Paulo, SP, BR.

2. Hospital Municipal Miguel Couto, Prof. Nova Monteiro Service of Orthopedics and Traumatology, Rio de Janeiro, RJ, Brazil.

3. University of lowa, Department of Orthopedics and Rehabilitation, lowa City, IA, USA

4. Hospital das Clínicas, Ribeirão Preto Medical School, Department of Orthopedics and Anesthesiology, Ribeirão Preto, SP, Brazil.

5. Hospital Israelita Albert Einstein, São Paulo, SP, Brazil.

\section{ABSTRACT}

Objectives: To describe the surgical treatment of fractures that involves the hallux interphalangeal joint, current indications and management options. Methods: we performed a literature review of relevant clinical studies in multiple databases, including PubMed, MedLine and Scopus, from January 1989 to October 2020. Results: There is consensus for surgical treatment of intra-articular fractures with a deviation greater than $2 \mathrm{~mm}$, metadiaphyseal fractures with malrotation and/or malangulation, open fractures and unstable fractures. Conclusion: The use of more rigid implants allow alignment maintenance during healing process and lower risk of reduction loss. Valgus deformity and interphalangeal joint osteoarthritis are possible complications that must be avoided. Level of Evidence III, Systematic review of Level III studies.

Keywords: Hallux. Fracture Fixation. Treatment Outcome.
RESUMO

Objetivos: destacar o tratamento cirúrgico das fraturas que envo/vem a articulação interfalangiana do hálux, suas indicações atuais e as opções de tratamento. Métodos: Realizamos uma revisão da literatura de estudos clínicos relevantes em múltiplas bases de dados, incluindo PubMed, MedLine e Scopus, de janeiro de 1989 a outubro de 2020. Resultados: Há consenso para o tratamento cirúrgico de fraturas intra-articulares com desvio superior a $2 \mathrm{~mm}$, fraturas metadiafisárias com má rotação e/ou malangulação, fraturas expostas e fraturas instáveis. Conclusão: O uso de implantes mais rígidos permite a manutenção do alinhamento durante o processo de consolidação e menor risco de perda da redução. As complicações que devem ser evitadas são a deformidade em valgo e a osteoartrite da articulação interfalangeana. Nível de Evidência III, Revisão sistemática de Estudos de Nível III.

Descritores: Hallux. Fixação de Fratura. Resultado do Tratamento.

Citation: Godoy-Santos AL, Giordano V, Cesar Netto C, Sposeto RB, Bitar RC, Wajnsztejn A, Sakaki MH, Fernandes TD. Hallux proximal phalanx fracture in adults: and overlooked diagnosis. Acta Ortop Bras. [online]. 2020;28(6):318-322. Available from URL: http://www.scielo.br/aob.

\section{INTRODUCTION}

Phalanx fractures of the toes are common. ${ }^{1}$ Hallux phalanx fractures represent the largest proportion of all toes phalanx fractures. ${ }^{2}$ However, hallux proximal phalanx fracture in adults has rarely been reported. ${ }^{3-6}$ Fractures of the hallux require surgical treatment much more often than other toe fractures due to the role of the first toe in weight bearing, balance, and pedal motion. ${ }^{7}$ Diaphyseal and articular fractures of the hallux proximal phalanx tend to consolidate in a good position with an appropriate initial treatment. When the principles of treatment for diaphyseal and intra-articular fractures are not respected, complications such as valgus deformity, decreased range of motion and interphalangeal joint (IPJ) osteoarthritis can lead to significant functional loss. ${ }^{8-10}$ The objective of our review is to describe the surgical treatment of fractures that involve the hallux interphalangeal joint, current indications and management options.

\section{MATERIALS AND METHODS}

We searched for relevant scientific literature from 1992 to 2019 in Electronic databases, such as PubMed, MedLine and Scopus. The keywords used are shown in Table 1.

All authors declare no potential conflict of interest related to this article.

The study was conducted at Laboratório Prof. Manlio Mario Marco Napoli, Departamento de Ortopedia e Traumatologia, Hospital das Clinicas, Medical School, Universidade de São Paulo. Correspondence: Alexandre Leme Godoy-Santos. Rua Dr. Ovídio Pires de Campos, 333, Cerqueira César, São Paulo, SP, Brazil, 05403010. alexandrelemegodoy@gmail.com 
Table 1. Keywords used to search the PUBMED, MedLine and Scopus database.

\begin{tabular}{c|c|c}
\hline \multicolumn{2}{c}{ Keywords for main PUBMED, MedLine and Scopus literature search } \\
\hline Hallux & Trauma & Phalanx \\
\hline Incidence & Fracture & Adults \\
\hline Prevalence & Fixation & Great toe \\
\hline Subheadings used for PUBMED, MedLine and Scopus literature search \\
\hline Complications & Lag screw & Radiology \\
\hline Outcome & Interphalangeal joint & Sports \\
\hline Plate & Diagnosis & Foot \\
\hline K-wire & Trauma mechanism & Injuries \\
\hline
\end{tabular}

We included case-control studies, cohort studies, epidemiological studies, and case reports, written in or translated into English, which described hallux phalanx fractures, treatment and complications.

Any available reports of hallux phalanx fractures we considered eligible. Studies that did not focus on this subject were excluded. The studies selected were read by the authors and judged on their contribution to the body of knowledge of this topic. The conduct and validity of any clinical studies was carefully considered, and the outcomes of management protocols were carefully scrutinized.

Other relevant case reports mentioning a specific association with the condition were also included. Only papers that made a significant contribution to the understanding of this condition were included in the review.

In total, 49 abstracts were selected, 31 of which were directly related to the hallux phalanx fractures.

\section{Epidemiology}

Understanding the epidemiology of fractures seems to be a challenge since the classic paper from Buhr et al. ${ }^{11}$

Epidemiological data on the foot and ankle injuries were obtained by authors who studied trauma-mechanism or site-specific epidemiology, ${ }^{12,13}$ and others who examined populationspecific epidemiology. ${ }^{14-19}$

An epidemiological study showed that $92.74 \%$ of all foot fractures were not work-related, $53.49 \%$ occurred outdoors and $26.12 \%$ occurred at patient's household. ${ }^{1}$

Shibuya et al. ${ }^{1}$ use the National Trauma Data Bank set from 2007 to 2011 to analyze the frequency and proportion of each fracture in the foot and ankle in major trauma hospitals in the United States. The authors found 280,933 foot and ankle fractures. Of those, 15,432 were phalanx fractures, which represent $5.49 \%$ of all foot and ankle fractures. Although metatarsal fractures were more common than phalangeal fractures, this study showed that the proportion of phalangeal open fractures was significantly higher than that of metatarsal fractures (33\% and $16 \%$, respectively). Moreover, approximately $20 \%$ of all phalanx fractures were open. ${ }^{1}$ In a study conducted in the United Kingdom, the authors observed 5,953 inpatient and outpatient fractures, of which $3.56 \%$ presented phalanx fractures (mean age: 35.3 years old). In fact, the hallux is the most fractured toe, representing the greatest proportion of all toe phalangeal fractures $(38-56 \%) .{ }^{20,21}$ In another study with 512,187 individuals who participated in the China National Fracture Survey, the authors found an incidence rate of foot fractures of 39.2/100000/year (95\%Cl: 33.8-44.7), 50.8/100000/year among men and 27.3/100000/year among women. ${ }^{22}$ Missed injuries and delayed diagnosis are some reasons for limited outcome of multiple trauma patients, in which foot injuries are often neglected. Fitschen-Oestern et al. ${ }^{23}$ observed $6.6 \%$ of missed/delayed toes fractures in 34,091 politrauma patients.

\section{Classification System}

The AO Foundation/Orthopaedic Trauma Association (AO/OTA) classification updated in 2018 is the most useful classification system. This coding system is well established, allowing a universal language standardization. ${ }^{24}$ In this system, the bone location should be determined first and the foot designation is 8 . Then in the subdivisions, phalanx fractures are designated as 88 . Toe identifiers are numerically determined as hallux:1, second toe:2, etc. The bone segments are numbered as proximal end segment $=1$, diaphyseal segment $=2$, and distal end segment $=3 .{ }^{25}$ The universal modifiers are descriptive terms of fracture morphology, displacement, associated injury, or location that are common to most fractures (Figure 1). They are generically divided in morphology of the diaphyseal fracture and morphology for the end segment fractures using letters (A, B, or C). ${ }^{25}$ As an example, great toe, proximal phalanx, distal end segment, partial articular fracture is classified as AO/OTA type 8811.3.B. ${ }^{24}$

\section{Phalanx 88 \\ Bone: Foot, phalanx 88

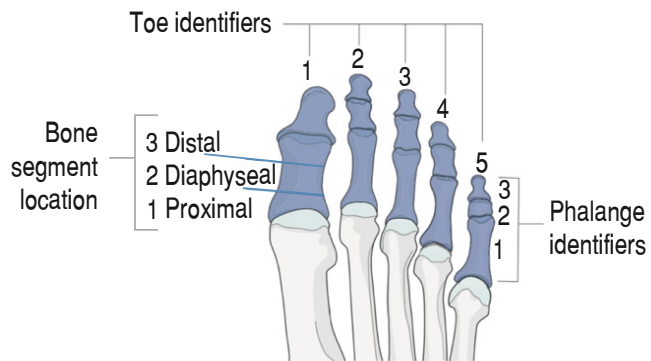 \\ - The toes and phalanges are identified as follows: \\ Toes: First or great toe $=1$; second toe $=2$; third toe $=3 ; f$ \\ ourth toe $=4$; and fifth toe $=5$. \\ Phalanges: Proximal phalan $x=1$; middle phalan $x=2$; and distal phalan $x=3$. \\ - The toe identifier plus phalanx identifier are added (between dots .....) \\ after the bone code. \\ - Example: Great toe, middle phalanx fracture is 88.1.2. \\ - The phalangeal bone segment location is then added. \\ - Anatomical region + bone.Toe.Phalanx.Bone segment location + Type \\ - Example: Great toe, middle phalanx, proximal end segment is 88.1.2.1}

Figure 1. AO Foundation/Orthopaedic Trauma Association coding classification system forefoot.

Source: $h$ ttps://surgeryreference.aofoundation.org/orthopedic-trauma/adult-trauma/foot-phalanges.

\section{Trauma mechanism}

A knowledge of the trauma mechanism is useful in understanding both the classification and the appropriate treatment. The three most common trauma mechanism patterns are twisting of the forefoot, axial trauma, and crushing. The forces producing these injuries are either direct (crush) or indirect (twist and axial). Specifically in hallux phalanx fractures, the two mechanisms commonly involved are axial trauma and crushing. ${ }^{4}$

Hallux fractures can occur to the distal phalanx and proximal phalanx with or without intra-articular involvement into the interphalangeal joint. A direct axial injury to the tip or tuff of the great toe usually lead to distal phalanx injury, whereas a crushing type of injury can lead to both proximal and distal phalanx injury.

Surgical treatment indications, approaches and fixation options In general, closed reduction is acceptable for treating hallux proximal phalanx diaphyseal fractures, being uncommon a surgical treatment. ${ }^{5}$ The main indications for the surgical treatment of the hallux proximal phalanx are:

- Intra-articular fractures with a deviation greater than 2mm;

- Metadiaphyseal fractures with malrotation; 
- Metadiaphyseal fractures with malangulation;

- Open fractures; and

- Unstable fractures.

The case reports of operative management show improved outcomes considering range of motion, pain, and deformity compared to nonoperative management. ${ }^{26-28}$

The recommendation of an operative approach and method fixation is usually based on the surgeon experience, fracture pattern, and size of fragments; they have been addressed in few studies. $5,6,9,10$

\section{Medial longitudinal approach}

This classic approach is recommended for fractures of the two phalanx of the hallux with or without joint involvement. However, this approach can also be used for open reduction and internal fixation (ORIF) of the medial sesamoid bone and distal fractures of the first metatarsal, as well as for treating complications. The skin incision starts at the mid-point of the phalanx base and runs distally towards the mid-diaphysis of the distal phalanx.

Some anatomical structures are at risk, such as the proximal phalanx, which receives its blood supply from an artery that enters the base, the dorsomedial (collateral) digital nerve (mostly a branch of the deep fibular nerve), which innervates the dorsal half of the medial side, and the medial plantar hallux nerve, which, in turn, innervates its plantar aspect. ${ }^{24}$

\section{Dorsomedial approach}

Surgical treatment for ORIF with this approach is mostly recommended for treating the displaced bicondylar fractures of the proximal phalanx of the hallux (>2 $\mathrm{mm}$ ). It could also be recommended for the treatment of displaced unicondylar or diaphyseal fractures of the proximal phalanx of the hallux. ${ }^{6}$ Dorsomedial approach presents the same structures at risk as the medial longitudinal approach.

\section{Dorsolateral approach}

This approach is recommended for treating the supra-intercondylar fracture of the proximal phalanx of the hallux with instability, malangulation, and malrotation, especially fractures with lateral displacement, which require implant on the lateral side of the proximal phalanx. It is performed medial to the vessels and lateral nerves of the hallux and no ligament or tendon detachment is necessary. ${ }^{29}$

Both dorsomedial and dorsolateral approach using L-shaped incision present higher risk for soft tissue blood supply compared to other approaches using straight incisions. ${ }^{6,9}$

Direct reduction should be performed using a periosteal elevator as a lever to reduce the fracture. Anatomical restoration of the articular surface is mandatory, with correction of axial rotation, length, and angulation. It is useful to apply a small pointed reduction clamp to temporarily compress the articular fracture fragments. Once the fracture is adequately reduced, a Kirschner wire (K-wire) is used, so the clamp can be removed, thus facilitating plate positioning. ${ }^{5,6,9,29}$ (Figure 2)

Implants options

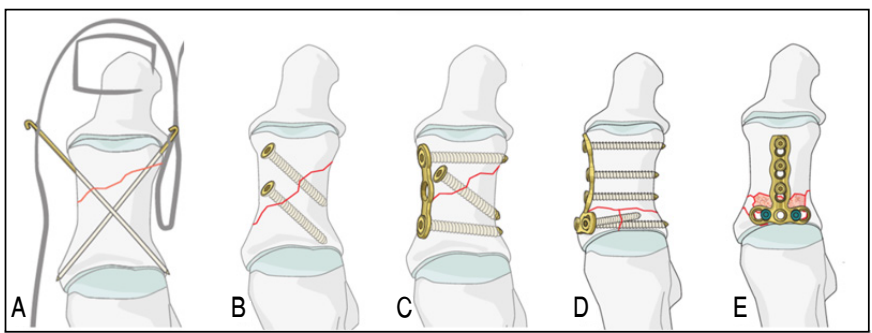

Figure 2. A: crossed K-wires; B: lag screws; C: lag screw and neutralization plate; D: neutralization plate and lag screw through plate; and E: "T" dorsal plate.

Source: https://surgeryreference.aofoundation.org/orthopedic-trauma/adult-trauma/foot-phalanges.
K-wires: when choosing closed reduction, the fixation with two or more K-wires may be performed. This fixation may be recommended for patients with poor soft tissue envelope or severe medical comorbidities.

Lag screw with $2.0 \mathrm{~mm}$ or $2.3 \mathrm{~mm}$ screws: recommended for simple fractures (spiral, oblique and transverse), extra-articular fractures, partial articular fractures, and complete articular fractures, which have inherent stability, thus making lag screw fixation sufficient. A plate to protect the lag screw fixation is rarely necessary.

Locking plate with $2.0 \mathrm{~mm}$ or $2.3 \mathrm{~mm}$ screws: recommended for wedge and multifragmentary fractures, or when a neutralization plate is needed. This plate enhances the degree of fixation and permits a greater degree of weight bearing, which facilitates functional rehabilitation. A lag screw may be used through the plate, since this combination increases the fixation strength

The plate must be adequately molded and to cut it in an appropriate length. If necessary, the plate can be bended and twisted to contour the bone (Figure 3).

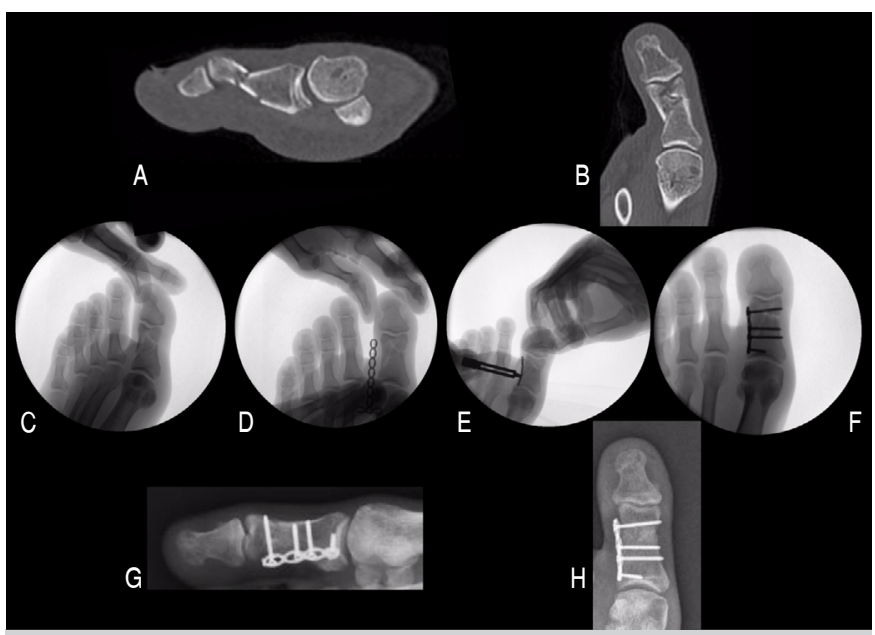

Figure 3. A and B: preoperative CT sagittal and axial view; C: intra-operative hallux distraction; $D, E$ and $F$ : plate cutting in an appropriate length, molding and bending to contour it to the bone; $\mathrm{G}$ and $\mathrm{H}$ : postoperative oblique and anteroposteior conventional radiographic images of hallux proximal phalanx fracture.

The plate should be applied to the tension side of the fracture to act as a tension band during plantar support. Moreover, the plate should have a low profile to reduce soft tissue irritation. ${ }^{29}$

\section{Complications}

Subungueal/nail hematoma can lead to potentially serious complications if not immediately identified and treated. It is more related with distal phalanx fracture than proximal phalanx fracture. ${ }^{5,30}$ A significant hematoma is defined as covering more than $50 \%$ of the nailbed surface beneath the nail plate.

- Type I injuries are described as relatively clean nail bed lacerations with less than $1 \mathrm{~cm}$ in length;

- Type II injuries are described as moderately contaminated nailbed lacerations without extensive soft tissue damage greater than $1 \mathrm{~cm}$ in length,

- Type III injuries are described as highly contaminated nailbed lacerations with extensive soft tissue damage to muscle, skin, and neurovascular structures.

Antibiotic administration and drainage are based on the type of injury. Partial nail plate avulsion should be treated non-surgically. 
If a laceration of nail plate is evident, then the nailbed should be completely cleaned up. Contour of the nailbed should be maintained for preventing onychodystrophy. Nonadherent sterile gauze should be used as a template and inserted into the proximal nail fold. ${ }^{30}$

\section{Valgus deformity}

Patients with a fracture of proximal phalanx of the great toe complain more about valgus deformity than about severe pain. ${ }^{10}$ Valgus deformity progresses gradually and can result in hallux valgus and interphalangeal hallux valgus according to the fracture site. Interphalangeal hallux valgus is defined as the angular relationship between the longitudinal axes of the proximal and distal phalanges. Normal values range from an average of $9^{\circ}$ in the unshod to $13.4^{\circ}$ in a shoe-wearing population. ${ }^{9}$

Fracture of the lateral side of the proximal phalanx head and/or diaphysis, and the medial side of the proximal phalanx base can result in valgus deformity. ${ }^{10}$

Treatment can be performed with arthrodesis or corrective osteotomy, depending on the degree of joint degeneration of the interphalangeal joint (IPJ).

\section{Hallux interphalangeal joint osteoarthritis}

Degenerative arthritis of the hallux IPJ may occur following hallux proximal phalanx fracture, more frequent in the proximal phalanx head and/or diaphysis., ${ }^{9,10}$

IPJ osteoarthritis is grading by radiographic system. ${ }^{31}$

- Grade I shows no degenerative change;

- Grade II shows mild degenerative changes with less than $1 \mathrm{~mm}$ of chondrolysis;
- Grade III shows moderate degenerative change with $1 \mathrm{~mm}$ to $2 \mathrm{~mm}$ of chondrolysis,

- Grade IV shows severe degenerative changes with joint destruction, cysts, or malalignment.

Arthrodesis of the IPJ of the hallux is performed for pain, deformity, or dysfunction secondary to hallux fracture.

Multiple approaches have been described, including longitudinal linear, transverse semi-elliptical, curvilinear, or L-shaped. ${ }^{32}$

Fixation used included single linear or multiple crossed K-wires (44\% non-union), intramedullary compression screw (10\% non-union) or 2.7-mm cortical lag screw. ${ }^{32,33}$

The optimal position in the sagittal plane has been reported to be from neutral to 5 or 10 degrees of plantar flexion to permit weight bearing on the toe pad. ${ }^{33}$

\section{CONCLUSION}

Fractures of the hallux and lesser toes phalanges are frequent injuries. Hallux phalanx fracture correspond to about $5.5 \%$ of foot and ankle fractures. The most frequent trauma mechanism is axial trauma. Foot trauma is often neglected in polytrauma patients. AO/OTA coding classification system allows a universal language standardization.

There is consensus for surgical treatment of intra-articular fractures with a deviation greater than $2 \mathrm{~mm}$, metadiaphyseal fractures with malrotation and/or malangulation, open fractures and unstable fractures. A surgery can be performed through medial longitudinal, dorsomedial and dorsolateral using L-shaped incision or straight incisions. The use of more rigid implants allow alignment maintenance during the healing process and lower risk of reduction loss. Valgus deformity and interphalangeal joint osteoarthritis are possible complications that must be avoided.

AUTHOR'S CONTRIBUTION: Each author contributed individually and significantly to the development of this article. ALGS: study conception and design and article writing; VG: study conception and design and article writing; CCS: result interpretation and manuscript writing. RBS: result interpretation and data collection; RCB: data collection; AW: data collection; MHS: critical review of the article; TDF: critical review of the article.

\section{REFERENCES}

1. Shibuya N, Davis ML, Jupiter DC. Epidemiology of foot and ankle fractures in the United States: an analysis of the National Trauma Data Bank (2007 to 2011). J Foot Ankle Surg. 2014;53(5):606-8.

2. Court-Brown CM, Caesar B. Epidemiology of adult fractures: a review. Injury. 2006;37(8):691-7.

3. Perlman MD. Fractures of the proximal phalanx of the hallux: the use of plates with displaced multifragment fractures. J Foot Surg. 1992;31(3):260-7.

4. Schenck RC Jr., Heckman JD. Fractures and dislocations of the forefoot: operative and nonoperative treatment. J Am Acad Orthop Surg. 1995;3(2):70-8.

5. Mittlmeier T, Haar P. Sesamoid and toe fractures. Injury. 2004;35(2):SB87-97.

6. Nishikawa DRC, Duarte FA, Cesar Netto C, Monteiro AC, Albino RB, Fonseca FCP. Internal fixation of displaced intra-articular fractures of the hallux through a dorsomedial approach: a technical tip. Foot Ankle Spec. 2018;11(1):77-81.

7. Hatch RL, Rosenbaum Cl. Fracture care by family physicians: a review of 295 cases. J Fam Pract. 1994;38(3):238-44.

8. Daly N. Fractures and dislocations of the digits. Clin Podiatr Med Surg. 1996;13(2):309-26

9. Salleh R, Beischer A, Edwards WH. Disorders of the hallucal interphalangeal joint. Foot Ankle Clin. 2005;10(1):129-40.

10. Kim S, Lee M, Seok S. Intra-articular fracture of proximal phalanx of great toe accompanied by valgus deformity associated with sports activities. J Orthop Surg. 2017;25(1):2309499017690324.

11. Buhr AJ, Cooke AM. Fracture patterns. Lancet. 1959;1(7072):531-6

12. Zhao HT, Wu HT, Wu WJ, Zhu L, Li BJ, Sun R, et al. [Epidemiological investigation of adult metatarsal fractures]. Zhonghua Yi Xue Za Zhi. 2010;90(1):15-8. Chinese.

13. Petrisor BA, Ekrol I, Court-Brown C. The epidemiology of metatarsal fractures. Foot Ankle Int. 2006;27(3):172-4.

14. Luciano AP, Lara LC. Epidemiological study of foot and ankle injuries in recreational sports. Acta Ortop Bras. 2012;20(6):339-42.
15. Kaplan LD, Jost PW, Honkamp N, Norwig J, West R, Bradley JP. Incidence and variance of foot and ankle injuries in elite college football players. Am J Orthop. 2011;40(1):40-4.

16. Tadros AM, Eid HO, Abu-Zidan FM. Epidemiology of foot injury in a high-income developing country. Injury. 2010;41(2):137-40.

17. Badekas T, Papadakis SA, Vergados N, Galanakos SP, Siapkara A, Forgrave $\mathrm{M}$, et al. Foot and ankle injuries during the Athens 2004 Olympic Games. J Foot Ankle Res. 2009;2:9.

18. Conti SF, Silverman L. Epidemiology of foot and ankle injuries in the workplace. Foot Ankle Clin. 2002;7(2):273-90

19. Wilson LS Jr., Mizel MS, Michelson JD. Foot and ankle injuries in motor vehicle accidents. Foot Ankle Int. 2001;22(8):649-52.

20. Eves TB, Oddy MJ. Do broken toes need follow-up in the fracture clinic? J Foot Ankle Surg. 2016;55(3):488-91.

21. van Vliet-Koppert ST, Cakir H, van Lieshout EM, de Vries MR, van Der Elst M, Schepers T. Demographics and functional outcome of toe fractures. J Foot Ankle Surg. 2011;50(3):307-10.

22. Liu S, Zhu Y, Wang L, Chen W, Zhang X, Zhang Y. Incidence and risk factors for foot fractures in China: a retrospective population-based survey. PLoS One. 2018;13(12):e0209740.

23. Fitschen-Oestern S, Lippross S, Lefering R, Besch L, Kluter T, Schenzer-Hoffmann E, et al. Missed foot fractures in multiple trauma patients. BMC Musculoskelet Disord. 2019;20(1):121.

24. Meinberg EG, Agel J, Roberts CS, Karam MD, Kellam JF. Fracture and dislocation classification compendium-2018. J Orthop Trauma. 2018;32(1):S1-170.

25. Watson-Jones R, Wilson JN. Watson-Jones fractures and joint injuries. 6th ed. Edinburgh: Churchill Livingstone; 1982.

26. Rapoff AJ, Heiner JP. Avulsion fracture of the great toe: a case report. Foot Ankle Int. 1999;20(5):337-9.

27. Wada K, Yui M. Surgical treatment of mallet toe of the hallux with the extension block method: a case report. Foot Ankle Int. 2011;32(11):1086-8.

28. Martin EA, Barske HL, DiGiovanni BF. Open surgical treatment of an acute, unstable bony mallet injury of the hallux. Foot Ankle Int. 2013;34(2):295-8

29. Godoy-Santos AL, Wajnsztejn A, Juncay MET, Cesar Netto C, Joannas GM, Giordano V. Technical tip: supra-intercondylar fracture of the proximal phalanx of the hallux. J Foot Ankle. Forthcoming 2020. 
30. Tucker DJ, Jules KT, Raymond F. Nailbed injuries with hallucal phalangeal fractures: evaluation and treatment. J Am Podiatr Med Assoc. 1996;86(4):170-3.

31. Coughlin MJ. Rheumatoid forefoot reconstruction: a long-term follow-up study. J Bone Joint Surg Am. 2000;82(3):322-41.
32. Frankel JP, Turf R, Tirone M. Arthrodesis of the hallux interphalangeal joint using a diagonally placed 2-mm. cortical bone screw. J Foot Surg. 1989;28(5):466-70.

33. Asirvatham R, Rooney RJ, Watts HG. Stabilization of the interphalangeal joint of the big toe: comparison of three methods. Foot Ankle. 1992;13(4):181-7. 